to be the case. The incidence of positive bone scans in the groups of patients classified according to their lymph node status is shown in table II. There was a very low pick up rate among patients with no tumour in the lymph nodes or with tumour confined to the low axilla only, but $16^{\circ}{ }_{0}$ of the patients with extensive lymph node disease had positive scans. In fact twothirds of the positive scans were found in patients with stage $C$ tumours. Of the nine patients with positive bone scans, seven also had tumour in the regional lymph nodes and would therefore have been identified histologically as having a poor prognosis. One of the two remaining patients had a false-positive scan (subsequent scans were normal) and the other died. Thus, of the total series of 192 patients, only one patient with a grave prognosis was identified exclusively by bone scanning.

The results of this study cast serious doubts on the value of bone scanning in the initial assessment of patients with apparently early breast cancer. It is an expensive method of

TABLE II-Numbers of positive bone scans according to tumour stage assessed histologically

\begin{tabular}{l|r|r|r}
\hline \multicolumn{1}{c|}{ Stage: } & A & B & C \\
\hline $\begin{array}{l}\text { No of patients } \\
\text { No with positive bone } \\
\text { scans }\end{array}$ & 98 & 56 & 38 \\
& 2 & 1 & 6 \\
\hline
\end{tabular}

confirming information that is more simply obtained by regional lymph node biopsy.

This work was first reported to the British Association for Surgical Oncology in London in December 1976.

We thank the radiographers and technicians of the departments of radiology and medical physics for carrying out the scans. In particular we are grateful for the help and co-operation of Mrs J C Lane and Mrs S E Black, and the secretarial help of Mrs P M Wheat, Miss J A Zuranska, and Mrs J Hirst.

\section{References}

1 Brinkley, D, and Haybittle, J L, Lancet, 1975, 2, 95.

${ }^{2}$ Ell, P J, Annals of the Royal College of Surgeons of England, 1975, 57, 313. ${ }^{3}$ Sklaroff, D M, and Charkes, N D, Surgery, Gynecology and Obstetrics, 1968, 127, 763.

${ }^{4}$ Galasko, C S B, British fournal of Surgery, 1975, 62, 694

${ }^{5}$ Galasko, C S B, Annals of the Royal College of Surgeons of England, 1972, $\mathbf{5 0 , 3 .}$

${ }^{6}$ Green, D, et al, Australia and New Zealand fournal of Surgery, 1973, 43, 251

'Blair, J S G, Clinical Oncology, 1975, 1, 185.

${ }^{8}$ Roberts, J G, et al, Lancet, 1976, 1, 237.

${ }^{9}$ Lentle, B C, et al, Surgery, Gynecology and Obstetrics, 1975, 141, 43.

${ }^{10}$ Citrin, D L, et al, Surgery, Gynecology and Obstetrics, 1976, 143, 360.

${ }^{11}$ Robbins, G F, et al, Cancer, 1972, 29, 1702.

\title{
Blood glucose control and glomerular capillary basement membrane thickening in experimental diabetes
}

\author{
C J FOX， S C DARBY， J T IRELAND， P H SÖNKSEN
}

British Medical fournal, 1977, 2, 605-607

\section{Summary}

Glomerular capillary basement membrane thickness (BMT) was measured in 23 rats which had had streptozocin-induced diabetes for 14 months and in 12 age-matched controls. Diabetic rats were randomly allocated to different groups, either receiving no treatment or treated with a low carbohydrate diet or insulin, or both. Control rats were randomly allocated to a normal or low carbohydrate diet.

Among the diabetic rats mean plasma glucose concentrations for the groups ranged from $27.4 \mathrm{mmol} / 1$ (494 $\mathrm{mg} / 100 \mathrm{ml})$ in the untreated rats to $9.8 \mathrm{mmol} / 1(177$ $\mathrm{mg} / 100 \mathrm{ml}$ ) in those receiving both a low carbohydrate diet and insulin. A highly significant positive relation was found between BMT and plasma glucose concentration for individual rats. When BMT was corrected for body weight a similar relation was observed.
These data indicate that hyperglycaemia is the main determinant in the development of basement membrane thickening.

\section{Introduction}

Despite improvements in health care vascular complications of diabetes mellitus create increasing morbidity and mortality. ${ }^{1}$ For example, diabetic retinopathy is the commonest cause of blindness under the age of $65 .^{2}$ Whether or not good diabetic control delays or prevents these complications is a question that remains unanswered. There is evidence that the structural changes in diabetic microangiopathy can result from hyperglycaemia. ${ }^{3}$ The first detectable lesion in the kidney is thickening of the glomerular basement membrane, which is the forerunner of more advanced disease that eventually leads to renal failure. ${ }^{4}$ Clinical studies have so far failed to determine the effect of diabetic control on the development and progress of nephropathy. Randomised clinical trials in man would be lengthy, expensive, and probably unethical. For these reasons we studied the effects of diabetic control on basement membrane thickening in rats.

\section{Methods}

Structure of colony-Male Wistar rats (mean body weight $290 \mathrm{~g}$ ) were given streptozocin $25 \mathrm{mg} / \mathrm{kg}$ intravenously in citrate buffer, $\mathrm{pH} 4 \cdot 4$, when they were 11 weeks old. Age-matched controls were injected with buffer alone. Eight weeks later capillary blood was taken from these rats in a fed state for measurement of plasma glucose 
concentration by a glucose oxidase method. The diabetic rats were stratified according to their plasma glucose concentration, and 10 weeks after streptozocin administration they were randomly allocated to one of four groups in such a way that mean plasma glucose concentration was the same in each group. Each group of rats was then given either no treatment and a normal diet (group 1); a low carbohydrate diet (group 2); daily insulin and a normal diet (group 3); or daily insulin and a low carbohydrate diet (group 4). Monocomponent porcine lente insulin was injected subcutaneously in a dose of $1 \cdot 2-2 \cdot 0$ IU daily. The normal diet groups were fed Spillers Laboratory Diet No 1, which had the following percentages of available calories: carbohydrate $65 \%$, protein $20 \%$, and fat $15 \%$. A low carbohydrate diet was prepared in our laboratory to give the following percentages of available calories: carbohydrate $40 \%$, protein $20 \%$, and fat $40 \%$. Non-diabetic control rats were divided into those receiving a normal diet and those receiving a low carbohydrate diet.

Mean plasma glucose-The mean plasma glucose concentration for individual rats (MPG) was the average of five values measured about every three and a half months. The first was the pretreatment value. The next three samples were taken in the fed state and two hours after insulin in the case of groups 3 and 4. The fifth sample was taken under anaesthesia using intraperitoneal tribromoethyl alcohol (Avertin, Winthrop Laboratories, Surbiton, Surrey) immediately before the animal was killed.

Analysis of renal tissue-Fourteen months after the onset of diabetes the surviving animals were killed, the kidneys quickly removed, and samples prepared for electron microscopy. All tissue was coded at the time of despatch to the electron microscopy unit, so that the examiner (JTI) was unaware of the treatment group to which any sample belonged. Gluteraldehyde-fixed sections of renal cortex, post-fixed in osmic acid, embedded in Araldite, and cut on an LKB ultramicrotome were examined in a Philips EM 200 transmission electron microscope. Random areas of glomerular capillaries were scanned at low power and loops facing Bowman's space were photographed at a constant magnification of 10000 . Cross-section measurements of basement membrane thickness (BMT) were made in the peripheral halves of capillary loops (fig 1) restricted to those parts which were cut in true cross-section. ${ }^{5}$ One-hundred consecutive measurements from random capillary loops were obtained from each kidney sample.

Statistics-The results were analysed using the general linear interactive modelling program.

\section{Results}

Thirty-five rats (six in each group except group 4, which contained five animals) survived until they were killed at 14 months. MPG and BMT corrected for body weight are shown in the table. When BMT

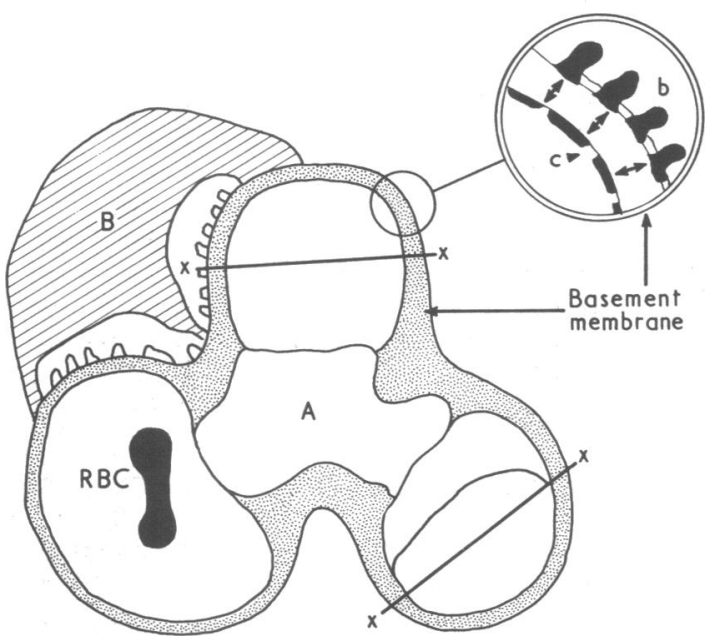

FIG 1 -Cross-section of glomerular lobule showing three capillaries attached to a central mesangial zone (A). Red blood cell (RBC) within capillary lumen shows scale of diagram. Epithelium (B) is attached to basement membrane by system of foot processes. Measurements are made in peripheral half of capillary loop (outside lines $x-x$ ). Inset shows detail of basement membrane in true cross-section suitable for measurement of thickness (arrowed) where epithelial pores (c) and gaps between epithelial foot processes (b) appear as spaces.
Mean plasma glucose (MPG), body weight, basement membrane thickness $B M T$ ), and BMT corrected for body weight in gomeruli from diabetic and normal rats subjected to different treatment regimens. Values are means $\pm S E$

\begin{tabular}{|c|c|c|c|c|c|}
\hline Group & $\begin{array}{l}\text { No of } \\
\text { rats }\end{array}$ & $\underset{(\mathrm{mmol} / \mathrm{l})}{\mathrm{MPG}}$ & $\begin{array}{c}\text { Body } \\
\text { weight } \\
\text { (g) }\end{array}$ & $\begin{array}{c}\mathrm{BMT} \\
(\mathrm{nm})\end{array}$ & $\begin{array}{c}\text { Corrected } \\
\text { BMT } \\
(\mathrm{nm} / \mathrm{g})\end{array}$ \\
\hline $\begin{array}{l}\text { (1) Diabetic, normal diet } \\
\text { (2) Diabetic, low } \\
\text { carbohydrate diet }\end{array}$ & $\begin{array}{l}6 \\
6\end{array}$ & $\begin{array}{l}27 \cdot 4 \cdot 2 \cdot 3 \\
21 \cdot 5+2 \cdot 7\end{array}$ & $\begin{array}{l}436+14 \\
444 \quad 29\end{array}$ & $\begin{array}{l}431 \div 18 \\
389 \div 15\end{array}$ & $\begin{array}{l}0.99 \pm 0.06 \\
0.90 \pm 0.08\end{array}$ \\
\hline $\begin{array}{l}\text { (3) Diabetic, insulin and } \\
\text { normal diet }\end{array}$ & 6 & $19 \cdot 8 \div 1 \cdot 0$ & $459+10$ & $414+8$ & $0.90 \pm 0.03$ \\
\hline $\begin{array}{l}\text { (4) Diabetic, insulin and } \\
\text { low carbohydrate diet }\end{array}$ & 5 & $9 \cdot 8: 2 \cdot 4$ & $604: 50$ & $400 \div 26$ & $0 \cdot 67 \pm 0.05$ \\
\hline $\begin{array}{l}\text { Non-diabetic, normal } \\
\text { diet }\end{array}$ & 6 & $6 \cdot 8+0 \cdot 3$ & $598+24$ & $305+10$ & $0.52+0.03$ \\
\hline $\begin{array}{l}\text { Non-diabetic, low } \\
\text { carbohydrate diet }\end{array}$ & 6 & $7 \cdot 1: 0 \cdot 3$ & $655+35$ & $349+22$ & $0.53 \div 0.03$ \\
\hline
\end{tabular}

Conversion: SI to traditional units-Glucose: $1 \mathrm{mmol} / \mathrm{l}=18 \mathrm{mg} / 100 \mathrm{ml}$.

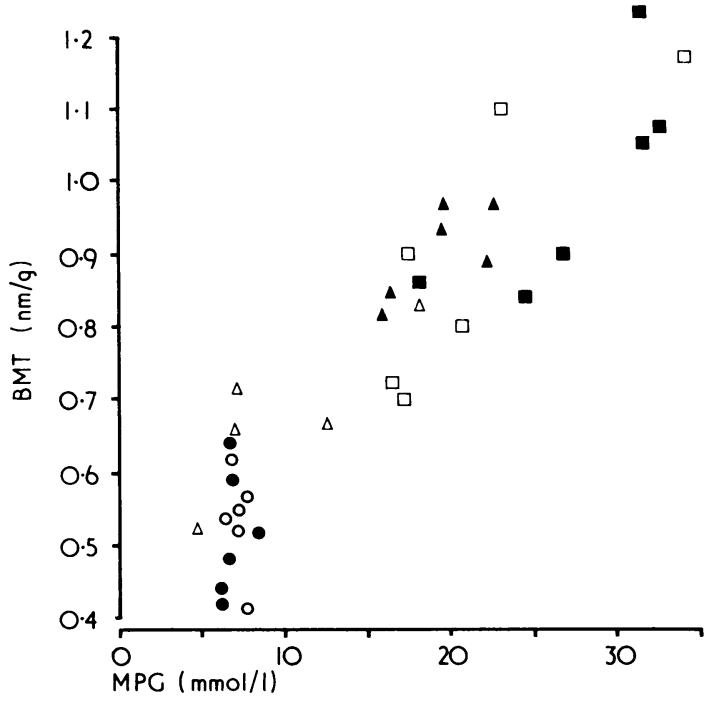

FIG 2-Relation between glomerular capillary basement membrane thickness (BMT) corrected for body weight and mean plasma glucose (MPG) in 35 rats. Rats on normal diet: $=$ non-diabetic; $\boldsymbol{\Delta}=$ diabetic with insulin; $\boldsymbol{\square}=$ diabetic without insulin. Rats on low carbohydrate diet: $\mathrm{O}=$ non-diabetic; $\dot{\Delta}=$ diabetic with insulin; $\square=$ diabetic without insulin.

Conversion: $S I$ to traditional units-Glucose: $1 \mathrm{mmol} / 1=$ $18 \mathrm{mg} / 100 \mathrm{ml}$

was regressed on MPG a significant positive relation was found: an increase of $1 \mathrm{mmol} / 1(18 \mathrm{mg} / 100 \mathrm{ml})$ in MPG was accompanied by an increase of $3.9 \mathrm{~nm}$ in the mean value of $\mathrm{BMT}(\mathrm{b} / \mathrm{SE}(\mathrm{b})=4.3, \mathrm{P}<0.001)$. When BMT corrected for body weight was regressed on MPG a similar relation was observed: an increase of $1 \mathrm{mmol} / 1$ in MPG was accompanied by an increase of $0.023 \mathrm{~nm} / \mathrm{g}$ in the mean value of corrected basement membrane thickness $(\mathrm{b} / \mathrm{SE}(\mathrm{b})=14 ; \mathrm{P}<0.001)$. This is shown in fig 2 . When BMT was regressed simultaneously on MPG and body weight the partial regression coefficient of body weight was significant $\left(\mathrm{b}_{\mathrm{BWT}} / \mathrm{SE}\left(\mathrm{b}_{\mathrm{BWT}}\right)=2 \cdot 12 ; \mathrm{P}<0.05\right)$.

The experiment was also considered as a $2 \times 3$ factorial design, the leyels of the first factor corresponding to normal or low carbohydrate diet and the levels of the second factor corresponding to no diabetes, diabetes, or diabetes treated with insulin. Separate analyses of variance were carried out on MPG body weight, BMT, and corrected BMT. For MPG there was a significant interaction between the two factors - that is, diet and diabetic status-the effect of diet varying according to diabetic status. The MPG of diabetic rats on a normal diet was $27.4 \mathrm{mmol} / \mathrm{l}(494 \mathrm{mg} / 100 \mathrm{ml})$ and somewhat lower $(21.5 \mathrm{mmol} / \mathrm{l}$ $(387 \mathrm{mg} / 100 \mathrm{ml})$ ) in the diabetic rats on a low carbohydrate diet. The MPG was generally lower in the diabetic rats receiving insulin and the difference between the two diets more pronounced: the mean in the low carbohydrate group was $9.8 \mathrm{mmol} / \mathrm{l}$ - only slightly above the non-diabetic values. For body weight at death there was no interaction between the factors (diet and diabetic status) but their two main effects were highly significant. The low carbohydrate diet increased body weight. The diabetic rats not receiving insulin were the lightest 
and the non-diabetic rats the heaviest. Diet appeared to have no effect on BMT, although diabetic status (second factor) had a highly significant effect. The values for BMT were very similar in all the diabetic groups and much higher than those for the non-diabetic rats. For BMT corrected for body weight the main effects of both factors were significant. The values were very similar in the two non-diabetic groups $(0.52$ and $0.53 \mathrm{~nm} / \mathrm{g})$ but increased in group $4(0.67 \mathrm{~nm} / \mathrm{g})$. Untreated diabetics had greatly increased values $(0.99 \mathrm{~nm} / \mathrm{g})$, while the thickening was almost as severe $(0.90 \mathrm{~nm} / \mathrm{g})$ in the poorly controlled diabetics on insulin or low carbohydrate diet alone.

\section{Discussion}

Insulin, in addition to its well-recognised effect on glucose homeostasis, is essential to body growth and development. ${ }^{6}$ In other words, normal growth and effective blood glucose control go hand in hand. This is borne out by our results, which showed that in streptozocin-diabetic rats treated with insulin plus a low carbohydrate diet (group 4) not only was glucose homeostasis (MPG) closest to normal but the body weight also reached control values. When BMT was corrected for body weight diabetic rats in group 4 had less BMT than other less wellcontrolled diabetic animals. It might seem paradoxical that hyperglycaemia should be associated on the one hand with poor body growth and on the other hand with excessive basement membrane thickening. There is, however, good experimental evidence to show how glucose is accumulated in the glycoprotein matrix of basement membrane in hyperglycaemic states. ${ }^{3}$ ? Although renal failure in diabetics is terminally associated with glomerulosclerosis complicated by fibrin deposition, hyalinisation, and often hypertensive changes, ${ }^{4}$ basement membrane thickening is the first step in the process.

The strong relation between basement membrane thickening and hyperglycaemia found in this study suggests strongly that blood glucose control rather than insulin administration determines BMT. Although we have dealt here with the relation between good diabetic control and morphological changes, we have also found in the same group of animals that plasma glucose concentration correlates inversely with motor nerve conduction velocity. ${ }^{*}$ These findings should offer encouragement not only to those who treat diabetic patients with the aim of maintaining good blood glucose control but also to those who search for improved methods of achieving this aim. ${ }^{9} 10$

We are grateful to Miss $\mathrm{V}$ Wright and $\mathrm{Mr} \mathrm{S}$ Terras for excellen technical help. The streptozocin was donated by $\mathrm{Dr} W \mathrm{E}$ Dulin Upjohn Corporation, Kalamazoo, Michigan, and the monocomponent insulin by Dr J Schlichtkrull, Novo Research Laboratories, Copenhagen. Financial support was provided by a Medical Research Council Project Grant, St Thomas's Hospital Research (Endowments) Committee, and the Higher Medicine Fund of the Greater Glasgow Health Board.

\section{References}

${ }^{1}$ Crofford, O B, Report of the National Commission on Diabetes to the Congress of the United States. United States Department of Health, Education and Welfare Publication No (NIH) 67-1018. Washington, DC, Government Printing Office, 1975.

2 Department of Health and Social Security, Incidence and Causes of Blindness in England and Wales, 1963-1968 by A Sorsby, p 33. London, HMSO, 1972.

${ }^{3}$ Spiro, R G, Diabetologia, 1976, 12, 1 .

Cameron, J S, Ireland, J T, and Watkins, P J, Complications of Diabetes, ed $\mathrm{H}$ Keen and J Jarrett, p 99. London, Arnold, 1975.

${ }^{5}$ Ireland, J T, Patnaik, B K, and Duncan, L J P, Diabetes, 1967, 16, 628.

${ }^{6}$ Sönksen, P H, Proceedings of the Royal Society of Medicine, 1975, 68, 707.

Beisswenger, P H, and Spiro, R G, Diabetes, 1973, 22, 180.

${ }^{8}$ Fox, C, Lowy, C, and Sönksen, P H, Clinical Science and Molecular Medicine, 1977, 52, 24P.

9 Lancet, 1975, 2, 909.

"Cahill, G F, Etzwiler, D D, and Freinkel, N, New England fournal of Medicine, 1976, 294, 1004.

(Accepted 15 fuly 1977)

\section{SIDE EFFECTS OF DRUGS}

\section{Hypertensive crisis in a patient given Sinemet, metoclopramide, and amitriptyline}

Many patients with Parkinson's disease are depressed. The patient described here, who was on amitriptyline, suffered a hypertensive crisis shortly after being given Sinemet (levodopa and carbidopa) and metoclopramide.

\section{Case report}

A 60-year-old housewife had had symptoms of Parkinson's disease for six months. An attempt to treat her as an outpatient with Sinemet had been abandoned because it produced intolerable nausea. She was therefore brought into hospital for control of her symptoms. On admission she was taking amitriptyline $20 \mathrm{mg}$ at night, together with digoxin $0.125 \mathrm{mg}$ and cyclopenthiazide $0.5 \mathrm{mg}$ in the morning, which her general practitioner had given her since he had found her blood pressure to be $190 / 100 \mathrm{~mm} \mathrm{Hg}$ two months earlier. On admission her blood pressure was $190 / 110 \mathrm{~mm} \mathrm{Hg}$.

She was started on Sinemet 110 (levodopa $100 \mathrm{mg}$, carbidopa $10 \mathrm{mg}$ ) half a tablet and metoclopramide $10 \mathrm{mg}$, each given thrice daily. Twenty-four hours later her blood pressure began to rise, and over 10 hours it rose from $170 / 110 \mathrm{~mm} \mathrm{Hg}$ to $270 / 140 \mathrm{~mm} \mathrm{Hg}$. She was flushed and complained of headache and breathlessness. Her pulse rate was 80 beats/minute and there were no signs of cardiac failure. After intravenous diazoxide $300 \mathrm{mg}$ her blood pressure fell, over two hours, to $150 / 80 \mathrm{~mm} \mathrm{Hg}$ and symptoms disappeared. A relationship between this hypertensive episode and the patient's treatment was not immediately suspected and her treatment was not changed. Nine hours after the first bolus of diazoxide her blood pressure again began to rise, over 12 hours, from $160 / 90 \mathrm{~mm} \mathrm{Hg}$ to $240 / 140 \mathrm{~mm} \mathrm{Hg}$; her pulse rate rose over the same interval from 80 to 140 beats/minute (sinus rhythm) and she again became flushed and breathless. After diazoxide $150 \mathrm{mg}$ intravenously, the blood pressure fell to $160 / 90 \mathrm{~mm} \mathrm{Hg}$ and there was again symptomatic improvement; her pulse rate fell to 80 beats/minute. Sinemet, metoclopramide, and amitriptyline were now discontinued. Her blood pressure remained at about $160 / 90 \mathrm{~mm} \mathrm{Hg}$ and pulse rate at about 80 beats/minute throughout the rest of her admission. Three 24-hour urinary vanillylmandelic acid estimations gave normal values.

On a subsequent admission three weeks later bromocryptine (in a final total dose of $25 \mathrm{mg}$ daily) and orphenadrine ( $50 \mathrm{mg}$ three times daily) were successfully and uneventfully used to control her Parkinsonism.

\section{Comment}

Its temporal relationship to the agents administered suggests that this hypertensive crisis was probably drug-related. An attempt to investigate it further by challenging the patient with the drugs singly or in combination was thought to be unjustifiable.

Although levodopa may rarely produce hypertensive responses, ${ }^{1}$ acute increases in blood pressure after administration of either Sinemet or carbidopa alone ${ }^{1}$ have not been reported. Metoclopramide blocks dopamine receptors but does not antagonise the common hypotensive effect of levodopa. ${ }^{2}$ On the other hand, metoclopramide has been shown to produce hypertensive crises in patients with phaeochromocytoma, ${ }^{3}$ possibly by causing catecholamine release from the tumour. Limited investigations for phaeochromocytoma in this patient were, however, negative. Amitriptyline given by itself has not been reported to cause pressor responses and this patient had been taking it for several weeks before the crisis occurred. Amitriptyline prevents 